\title{
Simple Subordinators in English Found in the Wolf of Wall Street
}

\author{
Made Detrichyeni Winaya ${ }^{1}$, Chatrina Natalia Sitompul ${ }^{2}$ \\ \{detrichyeni.winaya@gmail.com ${ }^{1}$, chatrina.sitompil@gmail.com ${ }^{2}$ \} \\ Universitas Warmadewa, Denpasar - Bali, Indonesia
}

\begin{abstract}
This study aims to identify simple subordinators in the Wolf of Wall Street novel and to analyse their meanings. The method used in this study is a descriptive qualitative method through library research. The main data of this study are taken from novel The Wolf of Wall Street. The data are collected by reading and classifying the meaning and the kinds of simple subordinators. As the result of the analysis found that there are three kinds of subordinators, they are subordinators of time, subordinators of reason/cause, and subordinators of condition. The subordinator expressing about time, they are as, when, since, while, before, after. The subordinator expressing about cause/reason commonly engineered by using: as, because, since. Clauses of reason and purpose are dependent clauses used to explain why or for what purpose something occurs. The subordinator expressing about condition is form of subordinate conjunction. It is commonly used and understood easily. It gives the addition of information. Coordination conjunctions set the standards under which the principle statement will be performed and demonstrated by if, that, and unless.
\end{abstract}

Keywords - Subordinators of time, subordinators of reason/cause, and subordinators of condition

\section{Introduction}

A sentence is a gathering of words that is used to communicate the ideas in writing or in speech. A simple sentence comprises of, at least, one subject and one verb. Generally, sentences can be divided into a simple sentence, compound sentence, complex sentence and compoundcomplex sentence. A simple sentence is called "simple" because it contains only one independent clause, while compound sentence has two or more independent clauses. In other words, compound sentence is a group of words with subjects and verbs which are connected by a coordinating conjunction. Then, a complex sentence commonly has one independent clause (main clause) and one or more dependent clause (subordinate clauses). Also, compoundcomplex sentence has two or more independent clause and one or more dependent clause [1].

As mentioned preceding that a sentence has one or more clauses. Clause is a unit of grammatical organization which is at least consist of a subject and predicate, for example:

We always found the teacher very helpful [2].

$\mathrm{S} \quad(\mathrm{A}) \quad \mathrm{V} \quad \mathrm{O} \quad \mathrm{C}$ 
Clauses are classified into an independent and dependent clause. An independent clause is a clause that stands alone as a complete sentence. It contains a subject and a verb and that makes sense when it stands alone. Whereas a dependent clause is a clause that could not be separated with main clause and followed by a conjunction, for instance:

Although I admire her reasoning, I rejected her conclusion [3].

Dependent clause Independent clause

The sentence above is complex sentence comprise of an independent clause (main clause) and a dependent clause (subordinate clause). A conjunction is a part of speech that connects words, phrases, and clauses (both dependent and independent) together. There are three different kinds of conjunction such as coordinator conjunction, correlative conjunction, and subordinate conjunction. Subordinating conjunction function to combine dependent clauses and independent clauses. Sometimes, subordinating conjunction refers to as subordinators or subordinate conjunctions, these important words and phrases may also introduce adverb clauses. Subordinating conjunction is essential part of complex sentences which include at least two clauses, with one of the clauses being subordinate (dependent). Subordinate conjunction has two roles namely clarify the importance of independent clause and provide a transition between two ideas in the same sentence. A typically, transition involves place, time, and cause and effect relationship.

Subordinate conjunction together with its following clause acts like a part of the other clause[4]. Subordinate conjunction can be found in social media and publications such as novels, magazines, newspapers, etc. Novel is one of the most popular publications. There are thousands of novels published in the world and many best-seller novels. Like common popular novels, The Wolf of Wall Street (2008) by Jordan Belfort. It can be found the sentence about subordinate conjunction in Novel The Wolf of Wall Street.

From the structural types of conjunction, subordinate conjunction is the most complex because is used to connect clauses of unequal rank. Conjunctions used to indicate time are after, before, since, until, till, when, whenever, while, now, that, as. Based on the explanation about the subordinate conjunction above, it shows that the process of subordinate conjunction has many problems for academic studies. The topic is complex and the functions are varied.

Related to this current issue, there are a plenty of researches that had been conducted preceding, such as in Liu's research [5] showed that relative clauses should be distinguished from subordinate clauses, which implies that words introducing relative clauses are not subordinators, and even among the markers of subordinate clauses some of them, such as before, because and if that indicates condition, are actually prepositions. There leaves a small class of subordinators for finite clauses, namely, that, whether and if that indicates interrogation. Moreover, Badaki, James, Jauro, and Adamu's research [6] showed that the faulty coordinators are based on positioning, redundancy and ordering of coordinators. Errors also occur in incomplete paired coordinators, wrong replacement of a coordinator with another coordinator or part of speech, faulty coordinator subordinator link and faulty coordinators that result from unranked coordination. Errors that concern subordinators are less frequent in the essays of senior secondary students. They occur as a result of faulty subordinators in unranked subordination and fault due to wrong replacement of subordinator with another subordinator or part of speech. Further studies can look at the semantic roles of coordinators and subordinators in meaning-bound analysis, can look at the frequency and types of coordinators and subordinators in the writings of students of a particular age, and can explicate the preponderance of a class of coordinators or subordinators in students' essays. Building on the 
previous researches, this present study aims to find out simple subordinators in The Wolf of Wall Street novel and their meanings.

\section{Method}

This study was designed in descriptive qualitative method. The main data used in this study is document namely novel the novel proposed by Jordan Belfort entitled the wolf of Wall Street. Library method is applied in this study in collecting the data. Furthermore, in analyzing the data some steps are done: first, read the data source from the novel; some sentences which are showing subordinate conjunction are underlined and quoted. Then the data are written on a paper and then the data is classified based on the relevant theory.

\section{Results and Discussion}

The subordinators can be divided into three kinds, such as subordinators of time, subordinators of reason/cause, and subordinators of condition. When a subordinator is added to a sentence the clause with the subordinator becomes a dependent clause that can't stand alone as a sentence. An unlike coordinators, subordinators do not give equal emphasis to the ideas they connect; instead, the clause that begins with a subordinator receives less emphasis. As mentioned previously, this study aims to find out simple subordinators in The Wolf of Wall Street novel and their meanings. Based on analysis, it was found that the three kinds of subordinators are applied in this novel. Thus, the discussion is described as follows.

\section{A. Subordinators of Time}

Related to subordinators of time normally establishes a period when performing the main clause. This subordinators are identify by some words like as, when, since, while, before, after. The following are subordinators which found in the novel that concern to time.

\section{After}

After is used to express that one event follows another. After is the action in an adverbial clause introduced by after will occur prior to the action in the main clause. For examples:

After a few seconds, the broker started shaking his head no (Belfort, 2008:61)

It was the pose of the mighty warrior after the fray. (Belford, 2008:103)

In the sentence (1), the subordinator after is at the beginning of the sentence, it combines two clauses namely dependent clause 'after a few seconds' and the independent clause 'the broker started shaking his head no'. Thus, the sentence becomes a complex sentence. The clause after in this sentence is a simple subordinator because the subordinator after consist of one word.

In sentence (2) after is simple subordinator which belongs to consist of one word. The subordinator after is in the middle of the sentence. The subordinator after connects two clauses namely the independent clause is it was the pose of the mighty warrior and dependent clause is after the fray. The meaning of subordinator after is to express time.

2. When

When shows that one event happens slightly after another. The subordinators when can introduce a clause that specifies a period during which the action in the main clause occurred.

For examples:

I would discuss that matter with Saurel when we met in a few hours. (Belford, 2008:144) 
When you make a purchase, the money will be automatically deducted from your account. (Belford, 2008:152)

In the sentence (1), the position of subordinator 'when' in the sentence above is in the middle of the complex sentence. There are two clauses in the sentence namely the independent clause is I would discuss that matter with Saurel and the dependent clause is when we met in a few hours. The subordinator when is simple subordinator because it consists of one word and the meaning is to express about time.

In the sentence (2) has a single word of simple subordinator. The subordinator when is at the beginning of the sentence. The subordinator when connects two clauses namely the dependent clause 'when you make a purchase' and the independent clause 'the money will be automatically deducted from your account'. Those clauses become a complex sentence. The subordinator when is a kinds of express time.

3. Before

Before is used to express that one event proceeds (comes before) another. Before is the action in an adverbial clause introduced by before after the action in the main clause. For examples:

Randall Franks walked up to me and grabbed my hand before I even had a chance to lift it.

(Belford, 2008:179)

I think we should move before something bad happens. (Belford, 2008:209)

In the sentence (1), the subordinator before is in the middle of the sentence. The subordinator before function to connect two clauses become complex sentence. The subordinator before is simple subordinator because subordinator before it consists of single word. The independent clause is Randall Franks walked up to me and grabbed my hand and the dependent clause is before I even had a chance to lift it. The meaning of subordinator before in this sentence is to express time.

In the sentence (2) indicates to simple subordinator before it is consist of one word. The meaning of subordinator before in the clause I think we should move before something bad happens is to express about time. The position of the subordinator before is in the middle of the sentence. This complex sentence was connected by two clauses namely independent clause ' $I$ think we should move' and dependent clause 'before something bad happens'.

4. Until

Until is used to express the time when an event or action comes to an end. Clauses introduced by until designate the endpoint of an action described in the main clause.

For examples:

I'm counting on you to make sure he stays until I do what I need to do. (Belford, 2008:109)

He would want all these things until he could figure them out on his own. (Belford, 2008:112)

In the sentence (1), the subordinator until is in the middle of the sentence. The meaning of subordinator until which is used to express time. The subordinator until function to connect two clauses namely the independent clause is I'm counting on you to make sure he stays and the dependent clause is until I do what I need to do. The two clauses becomes a complex sentence.

In the sentence (2) also has one word, which is filled by simple subordinator until in the clause He would want all these things until he could figure them out on his own which takes the subordinator until is in the middle of the sentence. The independent clause is He would want all these things and the dependent clause is until he could figure them out on his own. The meaning of subordinator until is to express time. 


\section{B. Subordinators of Reason/Cause}

Generally, cause conjunction is identify by word as, because, and since. Those words aimed to explain the activity of main clause. Based on the data analysis found some of them as provided in the following examples.

1. Because

It's the perfect job for me because I am lower than pond scum. (Belford, 2008:3)

I will tell you that you need to treat me better because I am nice girl and I could find other men. (Belford, 2008:198)

In the sentence (1), because is simple subordinator which belongs to consist of one word. The subordinator because is in the middle of the sentence. The subordinator 'because' connects two clauses namely independent clause and dependent clause become a complex sentence. The independent clause is filled by the clause it's the perfect job for me and the dependent clause is because I am lower than pond scum. The meaning of subordinator because is to express about reason.

In the sentence (2) above, the position of subordinator because is in the middle of the complex sentence. The sentence above is begun of the independent clause is I will tell you that you need to treat me better and the dependent clause is because I am nice girl and I could find other man. The meaning of the clause I will tell you that you need to treat me better, because I am nice girl and I could find other man is to express the reason.

2. Since

Since then I'd had two back surgeries, both of which had made the pain worse. (Belford, 2008:31)

He's been inconsolable ever since his fever broke. (Belford, 2008:379)

From the examples above, it can be seen that subordinator since is subordinating conjunction which is used to express a reason. In the sentence (1), the subordinator since is at the beginning of the sentence. The subordinator 'since' connects two clauses namely the dependent clause is since then I'd had two back surgeries and the independent clause is both of which had made the pain worse. The two clauses become a complex sentence, while subordinator since it simple subordinator because the subordinator since indicates to single word.

In the sentence (2), the subordinator 'since' connects two clauses in which the independent clause is he's been inconsolable ever and the dependent clause is since his fever broke. Those clauses has been in complex sentence. The subordinator since is in the middle of the sentence. The meaning of subordinator since is to express about the reason.

C. Subordinators of Condition

A condition is a form of subordinate conjunction. It is commonly used and understood easily. It gives the addition of information. Condition conjunctions set the rules under which the main clause will be performed and are indicated by if, that, and unless.

For examples:

1. Unless

Unless we can get it out manually, you could lose a great deal of blood. (Belford, 2008:356)

We're not going anywhere unless Captain Marc says it's safe. (Belford, 2008:395)

In the sentence (1), the position of subordinator unless is at the beginning of the sentence. The subordinator unless aims to connect two clauses become a complex sentence in which the dependent clause is unless we can get it out manually and the independent clause is you could lose a great deal of blood. The meaning of subordinator unless is to express about condition. As stated in the sentence (2), there is subordinator unless which is used to express the condition and the subordinator unless is in the middle of the sentence. The subordinator unless aims to 
connect two clauses namely the independent clause is we're not going anywhere and the dependent clause is unless Captain Marc says it's safe.

2. If

If I had to guess, she was probably yapping on the phone to one of her friends or disciples or whatever the fuck they were. (Belford, 2008:33)

If you wanted to see me or even speak to me, you first had to get through Janet. (Belford, 2008:55)

In the sentence (1), the subordinator if is used to express the condition. Subordinator if also belongs to consist of one word. If is subordinator, it is used to link a dependent clause to main clause. The dependent clause is if I had to guess and the independent clause is she was probably yapping on the phone to one of her friends or disciples or whatever the fuck they were. The position of subordinator if is at the beginning of the sentence. From the sentence (2) above, it can be seen that subordinator if is subordinate conjunction which is used to express the condition and usually comes first. The subordinator if is aims to connect two clauses to be complex sentence, namely the dependent clause is if you wanted to see me or even speak to me and the independent clause is you first had to get through Janet.

\section{Conclusion}

Grounded by the analysis of simple subordinators and their meanings found in the novel entitled The Wolf of Wall Street by Jordan Belford, thus it can be drawn the conclusions: subordinators are linking words just like coordinators that link to independent clause together. When a subordinator is added to a sentence the clause with the subordinator becomes a dependent clause that cannot stand alone as a sentence. The subordinators can be classified into simple subordinators and compound subordinators. Simple subordinators are subordinators consist of one word; after, when, before, because, since, unless, if, and until. The subordinators itself can be divided into three kinds, such as subordinators of time, subordinators of reason/cause, and subordinators of condition. The meaning of subordinators found in the novel is subordinator expressing about time, expressing about cause/reason, and expressing about condition. The subordinators of time normally establishes a period when performing the main clause. This subordinators are identify by words like as, when, since, while, before, after. The subordinator expressing about cause/reason is caused conjunctions illuminate the reason that the main clause activities were performed and are commonly engineered by using: as, because, since. Clauses of reason and purpose are dependent clauses used to explain why or for what purpose something occurs. The subordinator expressing about condition is form of subordinate conjunction. It is commonly used and understood easily. It gives the addition of information. Condition conjunctions set the rules under which the main clause will be performed and are indicated by if, that, and unless.

\section{Reference}

[1] Oshima, Writing Academic English: A Writing and Sentence Structure Workbook for International Students. 1983.

[2] R. Quirk, S. Greenbaum, G. Leech, and J. Svartvick, A Grammar of Contemporary English. London: Longman Group Ltd, 1972. 
[3] R. Quirk, A Comperhensive Grammar of the English Languge. New York: Longman, 1985.

[4] M. Swan, A Practical English Usage. New York: Oxford University Press, 1995.

[5] Y. Liu, "English Subordinators in Finite Clause: Definition and Classification," International Journal of English Linguistics, vol. 4, no. 4, pp. 55-62, 2014.

[6] J. V. Badaki, K. James, L. B. Jauro, and T. U. Adamu, "A Study of Faulty Subordinators and Coordinators in the Composition Writing of SS2 Students in Concordia College, Yola," International Journal of English Language and Linguistics Research, vol. 3, no. 3, pp. 11-25, 2015. 